\title{
Akut Lenfoblastik Lösemili Çocuklarda Motor Fonksiyonlar ile Yaşam Kalitesi ve Günlük Yaşam Aktiviteleri Arasındaki İlişkinin Araştırılması
}

\section{Investigation of the Association Between Motor Functions with Quality of Life and Daily Living Activities in Children with Acute Lymphoblastic Leukemia}

\author{
Vesile Yildiz Kabak ${ }^{1 *}$, Fulya Ipek ${ }^{1}$, Sule Unal ${ }^{2}$, Songul Atasavun Uysal ${ }^{1}$, Tulin Duger ${ }^{1}$ \\ ${ }^{1}$ Hacettepe Üniversitesi Fizik Tedavi ve Rehabilitasyon Fakültesi, Ankara, Türkiye, Department of Pathology, \\ Ankara, Turkey. \\ ${ }^{2}$ Hacettepe Üniversitesi Tıp Fakültesi, Pediatrik Hematoloji Departmanı, Ankara, Türkiye \\ e-mail: vesile_yldz@hotmail.com, fulyaipek92@gmail.com, suleunal@hacettepe.edu.tr, songula@hacettepe.edu.tr, \\ tduger@yahoo.com \\ ORCID: 0000-0002-1559-1793 \\ ORCID: 0000-0001-7606-042X \\ ORCID: 0000-0002-3083-8547 \\ ORCID: 0000-0001-7344-411X \\ ORCID: 0000-0002-3332-5958 \\ *Sorumlu yazar/ Corresponding Author: Vesile Yildiz Kabak \\ Gönderim Tarihi / Received: 11.12.2020 \\ Kabul Tarihi / Accepted: 26.01.2021 \\ DOI: $10.34087 /$ cbusbed. 839071

\section{$\ddot{O} z$}

Giriş ve Amaç: Çalışmamızın amacı, idame kemoterapisi alan akut lenfoblastik lösemili (ALL) çocuklarda motor fonksiyonlar ile yaşam kalitesi ve günlük yaşam aktiviteleri (GYA) arasındaki ilişkinin araştırılmasıydı.

Gereç ve Yöntemler: Çalışmamız, Hacettepe Üniversitesi Çocuk Hastanesi’nde gerçekleştirildi. Çalışmaya ALL tanısı alan ve idame kemoterapisine devam eden, 4 ve 15 yaşları arasındaki çocuklar dahil edildi. Motor fonksiyonlar, Bruininks-Oseretsky Motor Yeterlik Testi-2. Versiyon Kisa Formu, kavrama kuvveti, 9-Delikli Peg Testi ve 30-saniye Otur-Kalk Testi ile değerlendirildi. Çocuklar İçin Yaşam Kalitesi Ölçeği (ÇIYYKÖ)-Kanser Modülü yaşam kalitesi düzeyini belirlemede kullanıldı. Çocuklar İçin Fonksiyonel Bağımsızlık Ölçeği (WeeFIM) GYA düzeyini değerlendirmede kullanıldı.

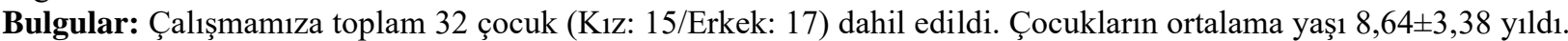
Korelasyon analizlerine göre, 30-saniye Otur-Kalk Testi ve bilateral koordinasyon skoru, ÇİYKÖ-Kanser Modülü skoruyla orta derecede koreleydi $(\mathrm{p}<0,05)$. WeeFIM toplam puanı ise Bruininks-Oseretsky Motor Yeterlik Testi-2. Versiyon Kısa Formu toplam puanı, kavrama kuvveti ve 9-Delikli Peg Testi skoru ile orta-yüksek derecede ilişkili bulundu $(\mathrm{p}<0,05)$.

Sonuç: ALL'li çocukların kemoterapi aldıkları dönemde motor becerilerindeki artış, günlük hayattaki fonksiyonelliğin ve yaşam kalitelerinin gelişmesi ile ilişkilidir. Bu sebeple, ALL tanısı almış çocuklar motor beceriler açısından dikkatli takip edilmelidir.

Anahtar kelimeler: Akut lenfoblastik lösemi, Çocuk, Fonksiyonel performans, Yaşam kalitesi.

\section{Abstract}

Objective: The aim of the present study was to investigate association between motor functions and quality of life level and activities of daily living (ADL) in children with acute lymphoblastic leukemia (ALL) receiving maintenance chemotherapy.

Materials and Methods: The present study conducted at Hacettepe University Children Hospital. Children diagnosed with ALL and continue to maintenance chemotherapy, between the age of 4 to 15 years were included. Motor functions were assessed using The Bruininks-Oseretsky Test of Motor Proficiency-Second Edition Short Form, grip strength, the 9-Hole Peg Test, and the 30-second Sit to Stand Test. The Pediatric Quality of Life Questionnaire (PedsQL)- 
Cancer Module was used to determine quality of life level. The functional independent measure for children (WeeFIM) was used to determine ADL.

Results: A total of 32 (Girl: 15/Boy: 17) children were included in the present study. The mean age of the children was $8.64 \pm 3.38$ years. According to the correlation analysis, the 30 -second Sit to Stand Test score and bilateral coordination score were moderately correlated with the PedsQL-Cancer Module $(\mathrm{p}<0.05)$. The WeeFIM score was moderate to highly associated with The Bruininks-Oseretsky Test of Motor Proficiency-Second Edition Short Form total score, grip strength, and the 9-Hole Peg Test score $(\mathrm{p}<0.05)$.

Conclusion: Increase in gross and fine motor functions provide to improve in functionality in daily life and quality of life level in children with ALL when receiving chemotherapy. For this reason, children diagnosed with ALL should be followed in terms of motor functions.

Keywords: Acute lymphoblastic leukemia, Children, Functional performance, Quality of life.

\begin{abstract}
1. Giriş
Akut lenfoblastik lösemi (ALL), çocukluk çağında en sık görülen kanser tipidir. ALL, tüm çocukluk çağı kanserlerinin dörtte birini oluşturur [1]. Tedavisi,

çalışmamızda amacımız, idame kemoterapisi döneminde ALL'li çocukların kaba ve ince motor fonksiyonel düzeylerini belirleyerek GYA ve yaşam kalitesi ile ilişkisini ortaya koymaktır.
\end{abstract} standart olarak indüksiyon, konsolidasyon ve idame kemoterapisi protokollerini içerir. Tedavilerdeki gelişmeler ile birlikte özellikle ALL'li çocuklarda să kalım oranı ciddi ölçüde artmıştır. Günümüzde sağ kalım oranı $\% 95$ 'lere ulaşmıştır [2,3].

İdame kemoterapisi kızlarda 120 haftalık, erkeklerde 146 haftalık ayaktan tedavi sürecini içermekte olup çocukların ALL risk grubuna göre alınan ilaç ve dozları değişebilmektedir. Bu dönemde alınan Methotrexate ve Vincristine gibi ilaçların fiziksel fonksiyonlar üzerine olumsuz etkileri yapılan çalışmalarda bildirilmiştir [4-7]. Kas kütlesi ve kuvvet kayb1, osteopeni/osteoporoz, duyusal problemler, denge problemleri, kaba ve ince motor fonksiyonlarda problemler tedavilere bağlı en sik karşılaşılan fiziksel problemlerdendir $[4,8,9]$. $\mathrm{Bu}$ problemler çocukların fonksiyonel kapasitesini olumsuz etkilemekte ve günlük yaşam aktivitelerinde (GYA) k1sitl1lıklar yaratabilmektedir. Fonksiyonel problemlerin yanı sıra çocuklardaki emosyonel problemler ve tedavilere bağlı kaygı, yaşam kalitelerini de olumsuz etkileyebilmektedir.

Literatüre bakıldığında ALL tanısı sonrası sağ kalan bireylerde fiziksel fonksiyonlar, emosyonel problemler ve yaşam kalitesi pek çok çalışmada araştırılmıştır [911]. Bu çalışmalarda fonksiyonel problemlerin kişilerin yaşam kalitesi ile yakın ilişkili olduğu bildirilmiştir [11]. Tanı sonrası sağ kalan çocuklarda fonksiyonellik geliştikçe yaşam kalitelerinin ve emosyonel durumlarının da olumlu yönde etkilendiği bildirilmiştir $[10,11]$. Bunun yanı sıra kanser tanısı sonrası sağ kalan çocukların fonksiyonel düzeyi iyileștikçe sosyal hayata katılımlarının da arttığı gösterilmiştir [9]. Hem fiziksel fonksiyonlar açısından hem de bu fonksiyonların bireylerin günlük hayatına, sosyal yaşamına ve yaşam kalitelerine olumlu yansımaları düşünüldüğünde fonksiyonel durum değerlendirmeleri her hastalıkta olduğu gibi kanserli bireylerde de önemlidir. Tedaviler dönemine özgü çocukların fonksiyonel düzeyi ve GYA'daki bağımsızlık durumu hakkında az sayıda çalışma bulunmaktadır $[4,12] . \quad \mathrm{Bu}$ çalışmalarda çocukların kemoterapi aldıkları dönemde fonksiyonel problem yaşadığı ve bu problemlerin çocukların GYA'daki durumuna da olumsuz yönde etki ettiğ bildirilmiştir [4,12]. Buradan yola çıkarak planlanan

\section{Materyal ve Metot}

$\mathrm{Bu}$ çalışma, Hacettepe Üniversitesi Çocuk Hastanesi Pediatrik Hematoloji Departmanı'nda gerçekleştirildi. Çalışmaya 4 ve 15 yaşları arasında olup ALL tanısı alan ve değerlendirmelerin yapıldığı süreçte ayaktan idame kemoterapisine devam eden çocuklar dahil edildi. Çalıșmanın yapıldığı bölümde idame kemoterapisi $\mathrm{St}$ Jude Total XV modifiye protokolüne göre standart olarak uygulanmaktaydı [6]. Ciddi kardiyovasküler, nörolojik, ortopedik, pulmoner, kognitif, emosyonel problemleri olan çocuklar çalışma dışında bırakıldı. Hacettepe Üniversitesi Girişimsel Olmayan Etik Kurulu'ndan 15.10.2019 tarihinde çalışma için gerekli onay alındı. (İzin Belgesi Numarası: GO 19/840) Çalışmaya dahil edilen tüm çocuklar ve ebeveynleri çalıșma hakkında bilgilendirildi ve onam formları kaydedildi. Değerlendirmeler, aynı fizyoterapist tarafindan yapıldı. Çalışmamız tanımlayıcı nitelikte bir araştırma olduğu için power analizi yapılamadı. Ancak, literatürdeki tedaviler döneminde fiziksel fonksiyonların incelendiğ araştırmalarda benzer örneklem sayısı dahil edildi [4,7]. 2.1.Demografik ve Medikal Bilgiler

Çocukların yaşı, boyu ve kilosu kaydedildi. Çocukların tanısı ve tanıdan sonra geçen süre hastane raporlarından kaydedildi.

\subsection{Motor Fonksiyonlar}

Çocukların kavrama kuvveti, Amerikan El Terapistleri Derneği'nin önerdiği standart protokole göre dijital dinamometre ile ölçüldü. Çocuklar arkası destekli ve kol desteği olmayan bir sandalyede oturtularak ölçümler yapıldı. Değerlendirmeler dominant taraf kol ile $3 \mathrm{kez}$ tekrar edilerek skorların ortalaması kaydedildi [13]. Çocukların motor yeterlilikleri Bruininks-Oseretsky Motor Yeterlik Testi-İkinci Versiyon Kısa Formu (BOT$2 \mathrm{KF}$ ) ile değerlendirildi. BOT-2 KF hem kaba hem de ince motor fonksiyonları ölçen bir test bataryasıdır. Sekiz alt başlık (ince motor keskinlik, ince motor entegrasyon, el becerisi, bilateral koordinasyon, denge, koşma hızı ve çeviklik, üst ekstremite koordinasyonu ve kuvvet) ve bu parametreleri ölçen testleri içerir [14].

İnce motor beceriler, 9-Delikli Peg Testi (9-DPT) ile değerlendirildi. Çocuklardan dominant tarafları ile 9 deliği yerlerine teker teker en kısa sürede yerleştirmeleri 
ve daha sonrasında çıkarmaları istendi. Görevi tamamlama süresi test skoru olarak saniye cinsinden kaydedildi $[15,16]$. Alt ekstremite motor performans1 değerlendirmek için ise 30-saniye Otur-Kalk Testi (30-sn OKT) kullanıldı. Çocuklar kol tutunma yeri olmayan bir sandalyede dizleri $90^{\circ}$ fleksiyonda oturur pozisyonda teste başlatıldı. Çocukların bu pozisyondan başlayarak ayağa kalkıp geri oturması ve bunu 30 saniyelik sürede mümkün olduğunca çok sayıda tekrarlaması istendi. Toplam ayağa kalkma sayısı, test skoru olarak kaydedildi [17].

\subsection{GYA}

Çocukların günlük yaşamdaki bağımsızlık düzeyleri Fonksiyonel Bağımsızlık Ölçeği (WeeFIM) ile değerlendirildi. $\mathrm{Bu}$ ölçek temel GYA başlığı altında incelenen kendine bakım, sfinkter kontrolü, mobilite, lokomasyon, iletişim ve sosyal iletişim aktivitelerini değerlendirir. Ölçek toplam 18 maddeden oluşur ve her bir madde, 1 (tam bağımlı) ile 7 (tamamen yardımsız) puan arasında skorlanır. Ölçeğin Türkçe güvenirlik ve geçerliliği, Küçükdeveci ve ark. tarafından yapılmıştır $[18,19]$.

\subsection{Yaşam Kalitesi}

Yaşam kalitesini değerlendirmek için Çocuklar İçin Yaşam Kalitesi Ölçeği (ÇİYKÖ) 3.0 Kanser Modülü kullanıld1. $\mathrm{Bu}$ ölçeğin 2-4, 5-7, 8-12 ve 13-18 yaşlarındaki çocuklar için ayrı formları vardır. Ölçeğin 24 yaş formu dişında diğer yaş grupları için hem çocuğa hem de ebeveyne çocuğunun yaşam kalitesi ile ilgili sorular soran iki ayrı formu bulunmaktadır. Ağrı ve acı, bulantı, işlemsel kaygı, tedavi kaygısı, endişe, bilişsel sorunlar, algilanan fiziksel görünüm ve iletişim olmak üzere toplam 8 alt başlık ve toplam 27 maddeden oluşur. Anketin Türkçe geçerlik ve güvenirlik çalışması yapılmıştır [20,21].

\subsection{Istatistiksel Analiz}

Tüm istatistiksel analizler SPSS Versiyon 23 kullanılarak yapıldı. Sonuçlar sayı ve yüzde (n, \%) veya Ortalama \pm Standart Sapma olarak gösterildi. Kolmogorov-Smirnov testi bulguların normal dağılıma uygunluğunu test etmede kullanıldı. Bulgular normal dağılıma uygunluk göstermediği için korelasyon analizleri Spearman correlation coefficient test kullanılarak yapıldı. Tüm analizlerde istatistiksel anlamlılık için $\mathrm{p}<0,05$ kabul edildi.

\section{Bulgular ve Tartışma}

\subsection{Bulgular}

Çalışmamıza toplam 32 ALL tanısı alan çocuk dahil edildi. Çocukların demografik ve medikal bulguları Tablo 1'de gösterildi. Tanıdan sonra geçen süre ortalama 2 yıldı. Çocukların GYA skorları genel olarak yüksekti. Yaşam kalitesi skoruna bakıldığında çocuktan çocuğa değişkenlik göstermekteydi.

Ölçülen parametreler arasındaki korelasyon düzeyleri Tablo 2'de gösterildi. Korelasyon analizi sonuçlarına göre, çocukların GYA düzeyi BOT-2 motor yeterlilik testi ve kavrama kuvveti ile kuvvetli ölçüde pozitif yönde ilişkiliydi $(\mathrm{p}<0,05)$.
Tablo 1. Çocukların Demografik ve Medikal Bulguları

\begin{tabular}{|l|l|}
\hline $\begin{array}{l}\text { Kaydedilen } \\
\text { Parametreler }\end{array}$ & $\begin{array}{l}\text { Ort. } \pm \text { S.S. (Min-Max }) \\
(\mathrm{n}=32)\end{array}$ \\
\hline Yaş, yıl & $8,64 \pm 3,38(4,5-15,5)$ \\
\hline $\begin{array}{l}\text { Cinsiyet, sayı } \\
\text { (Kız/Erkek) }\end{array}$ & $15 / 17$ \\
\hline $\begin{array}{l}\text { Tanıdan Sonra Geçen } \\
\text { Süre, ay }\end{array}$ & $25,64 \pm 8,40(12-38)$ \\
\hline $\begin{array}{l}\text { Vücut Kütle Indeksi, } \\
\text { kg/m² }\end{array}$ & $18,65 \pm 3,19(13,63-25,43)$ \\
\hline Wee-FIM Toplam Puan & $122,22 \pm 4,67(109-126)$ \\
\hline $\begin{array}{l}\text { ÇIYKÖ-Kanser Çocuk } \\
\text { Raporu }\end{array}$ & $75,21 \pm 14,49(48,07-100)$ \\
\hline BOT-2 SF Toplam Puan & $46,43 \pm 14,69(19-71)$ \\
\hline $\begin{array}{l}\text { 30-sn Otur-Kalk Testi, } \\
\text { sayı }\end{array}$ & $15,68 \pm 3,65$ (10-24) \\
\hline Kanrama Kuvveti, kgf & $9,62 \pm 6,92(0-27,36)$ \\
\hline
\end{tabular}

WeeFIM: Cocuklar İçin Fonksiyonel Bağımsılık Ölçeği, ÇiYKÖ: Cocuklar İçin Yaşam Kalitesi Ölçeği, BOT-2 SF: Bruininks-Oseretsky Motor Yeterlik Testi-İkinci Versiyon Kisa Formu, Ort.: Ortalama, SS: Standart sapma, Min: Minimum, Max: Maximum, n: Örneklem sayısı.

Tablo 2. Çocukların Yaşam Kalitesi ve Günlük Yaşam Aktiviteleri ile Motor Fonksiyonların İlişkisi

\begin{tabular}{|l|l|}
\hline Korelasyonlar & R değeri \\
\hline PedsQL \& 30-sn otur-kalk testi & $0,433^{*}$ \\
\hline PedsQL \& Bilateral koordinasyon & $0,407^{*}$ \\
\hline $\begin{array}{l}\text { Wee-FIM \& BOT-2 SF Toplam } \\
\text { Puan }\end{array}$ & $0,723^{*}$ \\
\hline Wee-FIM \& Kavrama kuvveti & $0,545^{*}$ \\
\hline Wee-FIM \& 9-delikli Peg Test & $-0,685^{*}$ \\
\hline
\end{tabular}

WeeFIM: Çocuklar İçin Fonksiyonel Bağımsızlık Ölçeği, ÇiYKÖ: Çocuklar İçin Yaşam Kalitesi Ölçeği, BOT-2 SF: Bruininks-Oseretsky Motor Yeterlik Testi-İkinci Versiyon Kisa Formu. Spearman Correlation Coefficient Test, ${ }^{*} \mathrm{p}<0,05$. 
Çalışmamızda ALL'li çocuklar tedavilerini ayaktan aldıkları dönemde fizyoterapist tarafindan değerlendirildi ve motor fonksiyonların GYA ve yaşam kalitesi ile ilişkisi araştırıldı. Elde edilen sonuçlara göre; ALL'li çocukların alt ekstremite motor performansı ve bilateral koordinasyon becerisinin yaşam kalitesi ile orta düzeyde ilişkili olduğu bulundu. Motor beceri toplam puan1, kavrama kuvveti ve ince motor becerileri ise GYA'da bağımsızlık düzeyi ile orta-yüksek düzeyde ilişkili olduğu gösterildi.

ALL'li çocuklar hastalık ve alınan tedavilere bağlı pek çok fiziksel problemler ile karşı karşıya kalmaktadır. Bu problemlerin yanı sıra, tedavi ve uygulanan işlemlere bağlı emosyonel problemler, yorgunluk, kusma ve bulantı gibi kemoterapinin yan etkileri sonucu çocukların fiziksel aktivite düzeyleri azalmakta ve daha sedanter bir hayat tarzını benimsemektedirler [22]. Bütün bu problemler çocuklarda fonksiyonel kayıplara yol açmakta, günlük aktivitelerini olumsuz yönde etkilemektedir. Fonksiyonel problemler özellikle hastanede yatış döneminde maksimum seviyede olup, taburculuk sonrası da görülmeye devam edebilmektedir [23]. Çalışmamızda hastanede yatış sonrası ayaktan tedaviye gelindiği dönemde ALL'li çocuklarda bu problemler incelendi. Motor fonksiyonların GYA ve yaşam kalitesi ile ilişkisi özellikle bu dönemde incelenerek çocukların uygun rehabilitasyon yaklaşımlarına yönlendirilmesi hedeflendi.

Çocukların kaba ve ince motor fonksiyonlarına bakıldığında, bu konuda daha önce yapılan çalışmaların skorları ile benzer sonuçlar elde edildi. Bu çalışmalarda BOT-2 motor yeterlilik testinde ALL'li çocukların sağlıklı çocuklara göre daha düşük skora sahip olduğu bildirilmiştir [24]. Çalışmamıza katılan ALL'li çocukların neredeyse hiçbiri daha önce bir fizyoterapi ve/veya rehabilitasyon hizmeti almamıştı. Bu durum bize ALL'li çocukların daha erken dönemden başlayarak motor fonksiyonları açısından değerlendirilmesi ve buna uygun egzersiz uygulamaları ile takip edilmesinin önemli olduğunu düşündürmüştür.

Çocukların GYA'daki bağımsızlık düzeyleri incelendiğinde genel olarak yüksek puan aldıkları tespit edildi. Literatürde ALL'li çocukların GYA'daki fonksiyonelliğini inceleyen sadece bir çalışmaya rastlandı. $\mathrm{Bu}$ çalışma hastanede yatış döneminde yapılmış ve Wee-FIM toplam skoru bizim çalışmamızdan daha düşük bulunmuştur [25]. Kemik iliği nakli uygulanan çoğunluğu lösemili çocuklardan oluşan ve hastaneden taburculuk sonrası dönemde yapılan bir başka çalışmamızda ise bu çalışmaya benzer bir Wee-FIM toplam skoru elde edilmişti [26]. Buna göre, hastanede yatış döneminde çocukların çevresel kısıtlılıktan dolayı GYA'da problemler yaşayabildiği, taburculuk sonrası ise GYA'da genel olarak bağımsızlık düzeylerinin iyi durumda olduğu söylenebilir.

Yaşam kalitesi açısından ALL'li çocukların aldıkları puanlar ülkemizdeki ÇiYKÖ kullanan çalışmalar ile kıyaslandığında, benzer bir sonuç elde edildiği görülmüştür [21]. Tedaviler döneminde yapılan diğer çalışmalarda da ALL'li çocukların tipik gelişim gösteren çocuklara göre daha düşük yaşam kalitesi skorlarına sahip olduğu kaydedilmiştir. Özellikle tedavilerin devam ettiği dönemde ALL'li çocukların yaşam kalitesinin iyileştirilmesine yönelik yaklaşımlar önem kazanmıştır. $\mathrm{Bu}$ dönemde çocukların semptomlarını en aza indiren müdahaleler ile egzersiz yaklaşımları çocukların kendilerini daha iyi hissetmelerine yardımcı olabilmektedir. Çalışmamızda bu konuya dikkat çekmeyi hedeflenerek yaşam kalitesi ile motor fonksiyonların ilişkisi araştırıldı. Lösemi çoğunlukta olmak üzere farklı çocukluk çağı kanser tanılarının dahil edildiği bir çalışmada kas kuvveti yaşam kalitesi ile ilişkili bulunmuştur [27]. Çalışmamızda benzer şekilde özellikle alt ekstremite motor fonksiyonlar ve bilateral koordinasyon becerisi geliştikçe yaşam kalitesinin arttığ tespit edildi. Buna göre bu alanda çalışan sağlık profesyonellerinin motor fonksiyonların değerlendirilmesi ve artırılması yönünden ALL'li çocukların fizyoterapi ve rehabilitasyona yönlendirmesinin önemli olduğu düşünülmüştür.

Yaşam kalitesine benzer olarak çalışmamızda çocukların GYA'daki bağımsızlık düzeyleri de motor fonksiyonlar ile ilişkili bulundu. Özellikle üst ekstremite motor becerileri ölçen kavrama kuvveti ve 9- Delikli Peg Testi ile Wee-FIM skorlarının ilişkili olması, GYA'da pek çok aktivitenin (giyinme, yemek yeme, kendine bakım gibi) üst ekstremite becerisi gerektirmesi sebebiyle olabilir. Buradan yola çıkarak, GYA'da sorunlar yaşayan ALL'li çocukların özellikle üst ekstremite kas kuvvetinin geliştirilmesi ve ince motor becerileri artırmak açısından aktivitelerin tedavi programlarına dahil edilmesinin önemli olduğu düşünülmüştür. Literatürde GYA ile ilgili sonuçlarımızı karşılaştırabileceğimiz başka bir çalışma olmaması sebebiyle, ALL'li çocukların motor fonksiyonlarının ve GYA'daki fonksiyonellik düzeylerinin daha fazla çalışmada araştırılmasına ihtiyaç olduğu görüldü.

Çalışmamız kesitsel bir çalışma olması sebebiyle kontrol grubu dahil edilemedi. ALL'li çocuklarda motor fonksiyonlar, GYA ve yaşam kalitesi düzeyinin tipik gelişim gösteren çocuklar ile kıyaslanarak ileriki çalışmalarda araştırılması daha kesin sonuçlar elde edilmesi açısından önemlidir. Ayrıca, çalışmaya dahil edilen çocukların fiziksel aktivite düzeylerinin kaydedilmesi sonuçlarımızın yorumlanması açısından önemli olabilirdi. İleriki çalışmalarda ALL'li çocukların tedavi aldıkları dönemde fiziksel aktivite düzeyli detaylı olarak incelenmelidir. Buna ek olarak, çalışmamızda örneklem sayısının yetersiz olması kaydedilen sonuçların regresyon analizi ile daha detaylı incelenmesini engellemiştir. İleriki çalışmalarda daha fazla örneklem sayısı ile motor fonksiyonlar ile ilişkili faktörlerin detaylı analiz edilmesi gereklidir.

\section{Sonuç}

Çalışmamız sonucunda idame tedavisi alan ALL'li çocukların kaba ve ince motor fonksiyonları ile yaşam kalitelerinin daha önce yapılmış çalışmalar ile kıyaslanarak tipik gelişim gösteren çocuklardan daha düşük olduğu, GYA'daki fonksiyonel düzeylerinin ise 
nispeten iyi düzeyde olduğu tespit edildi. Korelasyon analizine göre çocukların alt ekstremite motor fonksiyonlar ve bilateral koordinasyon becerilerinin geliştirilmesi ile yaşam kalitelerinin de artırılabileceği düşünüldü. Ayrıca, GYA'da fonksiyonel düzeyin özellikle üst ekstremite kas kuvveti ve ince motor beceriler geliștirilerek artırılabileceği bulundu. Bu alanda çalışan sağlık profesyonellerinin tanı sonrası en erken dönemde ALL'li çocukların motor fonksiyonlar açısından değerlendirilmesinin ve fizyoterapistlere yönlendirilmesi hem çocukların günlük aktivitelerini sürdürebilmesi hem de yaşam kalitelerinin yükseltilmesi açısından önemlidir.

\section{Teşekkürler ve Bilgilendirme}

Etik kurul izni Hacettepe Üniversitesi Girişimsel Olmayan Etik Kurulu'ndan 15.10.2019 tarihinde alınmıştır. Etik kurul izin belge numarası: GO 19/840.

\section{References}

1.Johnston, W.T, Erdmann, F, Newton, R, Steliarova-Foucher, E, Schuz, J, Roman,, E, Childhood cancer: Estimating regional and global incidence, Cancer Epidemiology, 2020, 101662.

2.Hunger, S.P, Loh, M.L, Whitlock, J.A, Winick, N.J, Carroll, W.L, Devidas, M, Raetz, E.A, Children's Oncology Group's 2013 blueprin for research: acute lymphoblastic leukemia, Pediatric Blood \& Cancer, 2013, 60, 957-63.

3. Gatta, G, Botta,, L, Rossi S, Aareleid, T, Bielska-Lasota, M, Clavel, J, Dimitrova N, etal., Childhood cancer survival in Europe 19992007: results of EUROCARE-5--a population-based study, The Lancet Oncology, 2014, 15, 35-47.

4.Hanna, S, Elshennawy, S, El-Ayadi, M, Abdelazeim, F, Investigating fine motor deficits during maintenance therapy in children with acute lymphoblastic leukemia, Pediatric Blood \& Cancer, 2020, 67 e28385.

5.Ness, K.K, Hudson, M.M, Pui, C.H, Green, D.M, Krull, K.R, Huang, T.T, Robison, L.L, Morris, E.B, Neuromuscular impairments in adult survivors of childhood acute lymphoblastic leukemia: associations with physical performance and chemotherapy doses, Cancer, 2012, 118, 828-38.

6. Pui, C.H, Relling, M.V, Sandlund, J.T, Downing, J.R, Campana, D, Evans WE, Rationale and design of Total Therapy Study XV for newly diagnosed childhood acute lymphoblastic leukemia, Annals of Hematology, 2004, 83, 124-6.

7. Reinders-Messelink, H, Schoemaker, M, Snijders, T, Goeken, L, van Den Briel, M, Bokkerink, J, Kamps, W, Motor performance of children during treatment for acute lymphoblastic leukemia, Medical Pediatric Oncology, 1999, 33, 545-50.

8. Söntgerath, R, Eckert, K, Impairments of Lower Extremity Muscle Strength and Balance in Childhood Cancer Patients and Survivors: A Systematic Review, Pediatric Hematology and Oncology, 2015, 32 585-612.

9. Yildiz Kabak, V, Calders, P, Duger, T, Mohammed, J, van Breda, E, Short and long-term impairments of cardiopulmonary fitness level in previous childhood cancer cases: a systematic review, Supportive Care in Cancer, 2019, 27, 69-86

10. Rueegg, C.S, Michel, G, Wengenroth, L, von der Weid, N.X, Bergstraesser, E, Kuehni, C.E, Physical performance limitations in adolescent and adult survivors of childhood cancer and their siblings, PloS one, 2012, 7, e47944.

11. Punyko, J.A, Gurney, J.G, Scott Baker, K, Hayashi, R.J, Hudson, M.M, Liu, Y, Robison, L.L, Mertens, A.C, Physical impairment and social adaptation in adult survivors of childhood and adolescent rhabdomyosarcoma: A report from the Childhood Cancer Survivors Study, Psycho-oncology, 2007, 16, 26-37.

12. Götte, M, Kesting, S.V, Winter, C.C, Rosenbaum, D, Boos, J, Motor performance in children and adolescents with cancer at the end of acute treatment phase, European Journal of Pediatrics, 2015, 174, 791-9.

13. Wind, A.E, Takken, T, Helders, P,J, Engelbert, R.H, Is grip strength a predictor for total muscle strength in healthy children, adolescents, and young adults? European Journal of Pediatrics, 2010, 169, 281287.

14. Deitz, J.C, Kartin, D, Kopp, K, Review of the Bruininks-Oseretsky Test of Motor Proficiency, Second Edition (BOT-2), Physical \& Occupational Therapy in Pediatrics, 2007, 27, 87-102.

15. Wang, Y.C, Magasi, S.R, Bohannon, R.W, Reuben, D.B, McCreath, H.E, Bubela, D.J, Gershon, R.C, Rymer, W.Z, Assessing dexterity function: a comparison of two alternatives for the NIH Toolbox, Journal of Hand Therapy, 2011, 24, 313-20.

16. Smith, Y.A, Hong E, Presson C, Normative and validation studies of the Nine-hole Peg Test with children, Perceptual and Motor Skills, 2000, 90, 823-43.

17. Jones, C.J, Rikli, R.E, Beam, W.C, A 30-s chair-stand test as a measure of lower body strength in community-residing older adults, Research Quarterly for Exercise and Sport, 1999, 70, 113-9.

18. Voll, R, Krumm, B, Schweisthal, B, Functional independence measure (FIM) assessing outcome in medical rehabilitation of neurologically ill adolescents, International Journal of Rehabilitation Research, 2001, 24, 123-31.

19. Küçükdeveci, A.A, Yavuzer, G, Elhan, A.H, Sonel, B, Tennant, A, Adaptation of the Functional Independence Measure for use in Turkey, Clinical Rehabilitation, 2001, 15, 311-9.

20. Varni, J.W, Burwinkle, T.M, Katz, E.R, Meeske, K, Dickinson, P, The PedsQL in pediatric cancer: reliability and validity of the Pediatric Quality of Life Inventory Generic Core Scales, Multidimensional Fatigue Scale, and Cancer Module, Cancer, 2002, 94, 2090-106.

21. Yıldız Kabak, V, Yakut, Y, Çetin, M, Düger, T, Reliability and Validity of the Turkish Version of the PedsQL 3.0 Cancer Module for 2- to 7-Year-Old and the PedsQL 4.0 Generic Core Scales for 5to 7-Year-Old: The Hacettepe University Experience, Turkish Journal of Haematology, 2016, 33, 236-43.

22. Tan, S.Y, Poh, B.K, Chong, H.X, Ismail, M.N, Rahman, J, Zarina, A.L, Juraida AR, Tahir A, Ruzita AT, Roslee R, Shanita SN, et al., Physical activity of pediatric patients with acute leukemia undergoing induction or consolidation chemotherapy, Leukemia Research, 2013, $37,14-20$

23. Green, J.L, Knight, S.J, McCarthy, M, De Luca, C.R, Motor functioning during and following treatment with chemotherapy for pediatric acute lymphoblastic leukemia, Pediatric Blood \& Cancer, 2013, 60, 1261-6.

24. Ness, K.K, Kaste, S.C, Zhu, L, Pui, C.H, Jeha, S, Nathan, P.C, et al., Skeletal, neuromuscular and fitness impairments among children with newly diagnosed acute lymphoblastic leukemia, Leukemia Lymphoma, 2015, 56, 1004-11.

25. Akbas, A.N, Uysal, M.F, Özengin, N, Akut lenfoblastik lenfomal çocuklarda hospitalizasyon sürecinde kas iskelet sisteminin durumu, uyku ve yaşam kalitesi: tanımlayıcı pilot çalışma, Adnan Menderes Universitesi Sağllk Bilimleri Fakültesi Dergisi, 2018, 2, 31-38.

26. Yildiz Kabak, V, Duger, T, Uckan Cetinkaya, D, Investigation of the Effects of an Exercise Program on Physical Functions and Activities of Daily Life in Pediatric Hematopoietic Stem Cell Transplantation, Pediatric Blood \& Cancer, 2016, 63, 1643-8.

27. Deisenroth, A, Söntgerath, R, Schuster A.J, von Busch, C, Huber, G, Eckert, K, Kulozik, A.E, Wiskemann, J, Muscle strength and quality of life in patients with childhood cancer at early phase of primary treatment, Pediatric Hematology and Oncology, 2016, 33, 393-407.

http://edergi.cbu.edu.tr/ojs/index.php/cbusbed isimli yazarın CBU-SBED başlıklı eseri bu Creative Commons Alınt1-Gayriticari4.0 Uluslararası Lisansı ile lisanslanmıștır. 